\title{
LA GUERRA DE AL-AZRAQ DE 1249
}

\author{
Por \\ ROBERT I. BURNS, S. J.
}

Preparando mi "Crusade against al-Azraq: A 13th-century Mudejar Revolt in International Perspective» (American Historical Review, febrero 1988) y mi "A Lost Crusade: Unpublished Bulls of innocent IV on al-Azraq's Revolt" (Speculum, en prensa), llegué a apreciar más claramente dos cartas de 1249 . La primera es un arbitraje entre el Infante Pedro de Portugal y Jaume el Conqueridor, dirigido por la esposa de Jaume, la reina Violant d'Hongria juntamente con un comité de hombres eminentes, y relativo a «la expulsión de los sarracenos" del gran feudo valenciano de Almenara-Castellón-SaguntoSegorbe, propiedad de Pedro. Muestra la guerra de al-Azraq en su fase de 1249 , en actividad sobre esta considerable zona del norte de Valencia, con la resistencia de Pedro a que el rey reemplazara los musulmanes de la zona por cristianos. Antonio Chabret publicó la carta hace un siglo en su Historia de Sagunto (2 vols. Barcelona, 1888, II, pp. 401-402); asimismo Fidel Fita en su más accesible "Concilios Tarraconenses" (Boletín de la Real Academia de la Historia, XL (1902), pp. 444-458). Dicha transcripción tiene casi dos docenas de errores, que si bien no son sustanciales, sí resultan fastidiosos. La he reeditado como el documento !.

La segunda carta muestra a los obispos de los Reinos de Aragón en concilio provincial, votando (por segunda vez en tres años) la "vigésima" cruzada internacional frente a la contínua guerra de al-Azraq. La "necesidad" de Jaume y "la voluntad y consentimiento" del Papa Inocencio IV dispusieron esta medida. La firman el arzobispo de Tarragona y cinco obispos, a la vez que los representantes de otros tres obispos, dos cabildos, y dos abades toman parte en su promulgación. Fita indujo a Francesc de Bofarull a transcribirla, pero la publicó confusamente como si fuera parte del acta del concilio («Concilios", pp.. 446-447, aclarado por la nota 9). Se edita aquí más cuidadosamente. Estas cartas indican en qué medida se generalizó la guerra de al-Azraq, y que el papado la consideraba ya una cruzada formal. Ambos temas, aquí bosquejados, resultan mucho más claros a la luz de las bulas papales publica- 
das en mis artículos arriba indicados. Considerando su duración, alcance, intensidad, y especialmente su reacción internacional según el papado, la "revuelta" de al-Azraq debe ser apreciada de nuevo como una "contracruzada" islámica o intento de reconquista. Su represión debe quedar como una empresa equivalente a las otras largas y desesperadas guerras musulmanas de Jaume en las Baleares, Valencia (desde 1232), Murcia y Valencia (desde 1275), como otra cruzada valenciana (desde 1247 y durante 1258 ).

(Trad. del inglés por Ovidio Carbonell)

A.C.A., Cancillería

Controversia vertebatur inter dominum lacobum dei gracia regem Aragonum et dominum Petrum infantem Portugalie super / expulsione Sarracenorum de Muro veteri et de Almenara et de Sogorb et de Castellione Burriane, et super populacione / dictorum locorum, ac super quadam summa peccunie quam dictus infans repetebat occasione predictorum castrorum ab ipso domino rege. I Tandem compromiserunt in dominam Yoles illustrem reginam Aragonum, promittentes stare dicto et voluntati eiusdem super / questionibus memoratis.

Nos itaque domina Yoles regina Aragonum, auditis racionibus utriusque partis de voluntate parcium et / assensu, habito consilio venerabilium Petri archiepiscopi terrachonensis et Fratris Andree valentini episcopi et Eximini Petri et aliorum sapien / tum, dicimus quod dominus rex donet infanti predicto decem milia solidorum regalium; et quod dum presens guer / ra Sarracenorum locorum circumstancium Murum veterem, Sogorbium, et Almenaram duraverit, teneatur dominus rex in ex / pensis suis custodire frontarias predictorum castrorum et providere in castro de Muro veteri XLV hominibus et in castro de Alme / nara XXXV hominibus et in castro de Sogorb XXXV hominibus et in castro de Castellione $V$ hominibus, quos dictus infans de / sua familia vel aliunde ad predictorum castrorum custodiam duxerit statuendos.

Item dicimus quod, non obstante quod in instrumentis / concambii que sunt inter dominum regem et infantem, contineatur quod ipse infans possit disponere et ordinare de possessionibus ipsorum / castrorum, predictus infans observet et ratam habeat populacionem quam dominus rex fecit in predictis locis, et instrumenta inde confecta / firmet vel alia de novo faciat si fuerit requisitus, nisi aliqua esset facta in ipsa populacione que digna essent retractacione, et talia / si essent dicimus quod dictus infans revocare ea possit de meo consilio et assensu.

Instrumenta tamen que sunt inter dominum regem et ipsum / infantem alias perpetuo in sua firmitate permeneant, ita quod ex hiis que acta sunt eisdem instrumentis in aliquo nullatenus / derogetur. 
Item dicimus quod dictus infans non teneatur servire domino regi per annum istum pro eo quod pro / ipso tenet in campo vel in civitate Terrachone.

Actum est hoc VI kalendas Marcii, anno domini MCCXL octa / vo, presentibus archiepiscopo, episcopo, et Eximino Petri supradictis, et Petro Cornelii et Guillelmo de Montecatano et / Stephano Petri et Eximino Petri de Pinna, Petro Nuniz et Guillemo Scribe et Guillelmo de Bello loco notario domini regis.

Pateat universis quod nos Petrus miseracione divina terrachonensis archiepiscopus; Poncius / dertusensis, Vitalis oscensis, Petrus barchinonensis, Guillelmus ilerdensis, et Andreas valentinus / epicospi; Petrus Albertus canonicus barchinonensis, procurator sui capituli ac Berengarii gerundensis episcopi; / Berengarius Burdi procurator Bernardi vicensis episcopi; Benedictus de Pratis procurator / urgellensis episcopi; Petrus de Lerato cantor ilerdensis, procurator eiusdem capituli; / et Sancius de Boleya canonicus procurator oscensis capituli; Geraldus sacrista cesaraugustanensis / procurator cesaraugustenensis episcopi; et Sancius Petri procurator tirasonensis episcopi; Frater Dalmacius / rivipollensis et Frater Petrus Sancti Cucuphatis abbates; in Terrachone concilio congregati: /

Attendentes quod vos dominus lacobus dei gracia rex Aragonum, zelum fidei catholice / habentes pre oculis, ad expulsionem Sarracenorum de regno Valencie attenta solfici / tudine laboratis, vestram eciam necessitatem et utilitatem nostram propiam in parte huius re / putantes, de domini pape voluntate atque assensu, promittimus vobis quod preter / vicesimam nostrorum reddituum istius anni, quam hoc anno apud Dertusam vobis dare / promisimus, vicesimam nostrorum reddituum sequentis anni vobis dabimus in subsidium / negocii memorati.

Ita quod usque ad kalendas lunii proximas primi anni vicesima, I et a proximis kalendis lunii usque ad annum alterius sive secundi anni vicesima, vobis / vel cui volueritis compleantur.

Actum est hoc idus Marcii, anno domini MCC / quadragesimo VIII. Ego Petrus sancte terrachonensis ecclesie archiepiscopus / subscribo (2).

(1) $22 \frac{1}{2} \mathrm{~cm} . \times 21 \frac{1}{2}$. Validación “ABC" escrita tres veces bajo el lado izquierdo y a través. Seis agujeros en losange en la parte inferior probablemente para sellos. Dorso: seflo de archivo, número escrito a lápiz, antigua locał́ización (Arm. del regne e València, bolsa D, n. ${ }^{\circ} 293$ ).

(2) $16 \mathrm{~cm} . \times 22 \frac{1}{2}$ (sin doblar). Dos emblemas notariales hechos al azar ante las firmas de los obispos. No hay sellos. Dorso: sello de archivo, número a lápiz (C-88, 1150 ), antigua localización (Arm. de Catt. 
Ego Poncius dertusensis episcopus subsubscribo [sic].

Ego Vitalis oscensis episcopus subscribo.

Ego Frater Petrus barchinonensis episcopus subscribo.

Ego Frater Guillelmus ylerdensis episcopus subscribo.

Ego Frater Andreas valentinus episcopus subscribo.

Ego Guillelmus de Alarico, notarios domini archiepiscopi supradicti, hoc scripsi mandato omni / um predictorum, die et anno prefixis.

bolsa $B$ ). "Concessio facta domino regi lacobo antiquo, per episcopos in terrachonensi concilio de vicesima redituum suorum ad annum, racione guerre Sarracenorum".

(3) Las firmas son personales, con rótulos y tamaños diferentes. Antecedían dos símbolos históricos, donde terminan las firmas dos $y$ tres. 